\title{
Houses for early weaned piglets : influence of rearing on the floor or in batteries, temperature and feeding on the periormances of the animals
}

\author{
J. LE DIVIDICH, A. AUMAITRE, L. BINA, J. RETTAGLIATI \\ Station de Recherches sur l'lilevage des Porcs, I. N.R. A., C. N. R. Z., \\ 78350 Jouy en Josas
}

This trial was made on a total of $\mathbf{1} 44$ piglets from 24 litters (6 homogenous piglets per litter) distributed into 3 groups in order to determine the influence of rearing conditions (housing, room temperature) and feeding on the animals performances between weaning at $36 \pm 3$ days and 70 days of age.

Housing characteristics were the following :

- Traditional rearing house, concrete floor with straw, room temperature $17^{\circ} \pm 1,5^{\circ}$ relative humidity $70 \pm$ IO p. roo, continuous housing of the animals (group I).

- Weaning house with flat-deck batteries on wire floor divided into 2 compartments : one at $\mathrm{I}^{8} .4^{\circ} \pm \mathrm{I}^{\circ} \mathrm{C}$, relative humidity $6 \mathrm{I} \pm \mathrm{I}$ o p. roo (group 2), the other at $2.3 .3^{\circ} \pm \mathrm{I}^{\circ} \mathrm{C}$, relative humiclity $5 \mathrm{I} \pm \mathrm{I}$ p. IOO (group 3), all-in-all-out housing system.

During the 2 weeks (period I) following weaning, the piglets received the same feed containing 5 p. 1 oo skim-milk powder and during the 3 following wecks (period II), skim-milk powder was not adcled to the diets of half of the animals.

Growth rates $(\mathrm{g} / \mathrm{d})$ of the animals reared on the floor and in batteries were the following: $I_{4} 8$ and 236 (period I), +2.5 and 495 (period II), i. e. differences in favour of the animals reared in batteries ranging from $\mathrm{I} 6$ to $60 \mathrm{p}$. $100(\mathrm{P}<0.05)$ according to the period of measurement. The health of the piglets estimated by number of days with diarrhoea per animal and per period was also better in the latter animals.

For piglets reared in batteries, the performances obtained at $18^{\circ} \mathrm{C}$ or at $23^{\circ} \mathrm{C}$ were not significantly different when the diet contained skim-milk : 233 g gain per day at $\mathrm{I} 8^{\circ} \mathrm{C}$ versus $24^{\circ} \mathrm{g}$ at $23^{\circ} \mathrm{C}$ (period I) and 523 versus 524 (period II) Suppression of the milk caused a significant lowering $(\mathrm{P}<0.05)$ of the growth rate only in the animals kept in batteries at a temperature of $\mathrm{I} 8^{\circ} \mathrm{C}$ (significant interaction between the temperature and the dict).

These findings show the impact of the mode of rearing (on the floor or in battery) and of honsing conditions (all-in-all-out system) on the performances of weaned piglets.

Furthermore, piglets weancd at 5 weeks and placed in batteries can be reared at a room temperature of $18^{\circ} \mathrm{C}$ provided that the diet contains skim-milk powder. 